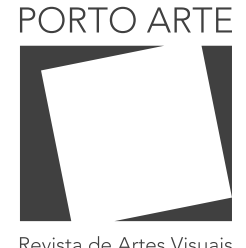

1.25 n. 44 Jul/dez 2020 e-ISSN: 2179-8001

\title{
A Estética da Descolonização em Psicoterapia: Psicoterapia Institucional e o Paradigma Ético-Estético de Fanon ${ }^{1}$
}

The Aesthetics of Decoloniality in Psychotherapy: Institutional Psychotherapy and Fanon's Ethico-Aesthetic Paradigm

\section{Anthony Faramelli}

ORCID: 0000-0002-1303-9719

Goldsmiths, University of London, United Kingdom

\section{Resumo}

Este artigo examinará como o colonialismo e o racismo estratificam o espaço, com foco especial na produção estética e na forma como a liberdade de um indivíduo depende do "ambiente" do espaço que ele ocupa. A análise será fundamentada na psiquiatria colonial argelina e na psicoterapia anti/de-colonial. Através de uma análise do trabalho de Frantz Fanon da Psicoterapia Institucional no Hospital Blida-Joinsville, este artigo argumentará que a política decolonial de Fanon e seu compromisso com a desalienação dependeram da (re) construção do espaço dentro do hospital. Isso também se soma ao que mais tarde Félix Guattari chamaria de "coeficiente de transversalidade". Por implicação, o argumento deste artigo pretende utilizar a abordagem espacial de Fanon para psicoterapia, a fim de obter uma leitura da Psicoterapia Institucional em massa como tendo, em seu cerne, um foco na produção espacial e estética.

Palavras-chave:

Psicoterapia institucional. Fanon, estética. Crise. Colonialismo.

\begin{abstract}
This article will examine how colonialism and racism stratifies space, with particular focus on aesthetic production and the way in which an individual's freedom is dependent on the "ambience" of the space they occupy. The analysis will be grounded in Algerian colonial psychiatry and anti/de-colonial psychotherapy. Through an examination of Frantz Fanon's application of Institutional Psychotherapy in Blida-Joinsville Hospital, this article will argue that Fanon's decolonial politics and his commitment to dis-alienation were reliant on the (re)construction of space within the hospital so as to increase what Félix Guattari would later refer to as the "coefficient of transversally". By implication, this article's argument intends to use Fanon's spatial approach to psychotherapy in order to elicit a reading of Institutional Psychotherapy en masse as having, at its heart, a focus on spatial and aesthetic production.
\end{abstract}

Key Words

Institutional psychotherapy. Fanon. Aesthetics. Crisis. Coloniality. 


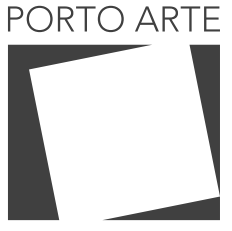

Revista de Artes Visuais

v $25 n .44$

$\mathrm{Jul} / \mathrm{dez} 2020$ e-ISSN: 2179-8001

\section{Introdução}

Em muitos aspectos, o século XXI tem sido um período de crises. Estamos vivendo uma crise econômica, uma crise de saúde mental, uma crise habitacional, Brexit e a crise européia e, é claro, uma crise de saúde pública. O século XXI parece ser marcado por uma crise permanente que está rompendo as bases da modernidade e as suposições que a sustentam. "As crises já não irrompem, ao contrário, elas permeiam tudo", de tal forma que a época neoliberal é melhor entendida como uma crise onipresente (Faramelli, Hancock e White 2018: 2). Nenhum ano se destaca como mais exemplar da época das crises do que o ano de 2020. A crise global de saúde pública causada pelo Covid-19 expôs desigualdades raciais estruturais, garantindo que a pandemia terá ramificações muito além da biologia.

O assassinato de George Floyd pela polícia de Minneapolis provocou uma crise de raça e racismo que tem sido sentida em todo o mundo. Esta crise fez brilhar uma luz sobre a colonialidade ${ }^{1}$ de nossas instituições e forçou uma conversa sobre as formas pelas quais "tipos" de pessoas são capazes de ocupar espaço. As palavras finais de de George Floyd, "não consigo respirar", falam da forma como as pessoas racializadas são confinadas em, eliteralmente sufocadas, por sistemas racistas. Na verdade, os sistemas de racismo são aplicados através do poder carceral que estratifica e controla o espaço, impedindo a liberdade ao ponto de asfixiar literalmente. Esta é uma produção de um ambiente dependente de uma estética de espaços disciplinares fechados, que criam um ambiente ou uma atmosfera de penalidade.

Este artigo examinará como o colonialismo e o racismo estratificam o espaço, com foco especial na produção estética e na forma como a liberdade de um indivíduo depende do "ambiente" do espaço que ele ocupa. A análise será fundamentada na psiquiatria colonial argelina e na psicoterapia anti/de-colonial. Através de um exame da aplicação de Frantz Fanon da Psicoterapia Institucional no Hospital Blida-Joinville, este artigo argumentará que a política decolonial de Fanon e seu compromisso com a desalienação dependiam da (re)construção do espaço dentro do hospital para possibilitar o que Félix Guattari mais tarde chamaria de "coeficiente de transversalidade". Por implicação, o argumento deste artigo pretende utilizar a abordagem espacial de Fanon para psicoterapia, a fim de obter uma leitura da Psicoterapia Institucional em massa como tendo, em seu cerne, um foco na produção espacial e estética. Finalmente, este artigo concluirá comentando a relevância que a prática ético-estética de Fanon tem para o ativismo anti-racista contemporâneo.

\section{Crise, raça e o sujeito colonial patologizado}

"Crise" é um termo que tende a ser mal compreendido e inadequadamente utilizado para significar um momento de ruptura potencialmente terminal na vida social e/ ou psíquica. A etimologia da crise vem da antiga palavra grega kpíøıs, krísisis, o poder

1- A forma como os sistemas coloniais continuam a estruturar relações interpessoais, sociais, políticas, culturals, econômicas, etc 


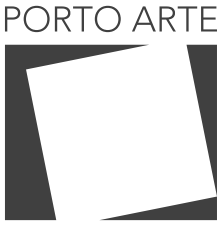

Revista de Artes Visuais

v. 25 n. 44

$\mathrm{Jul} / \mathrm{dez} 2020$ e-ISSN: 2179-8001

de distinguir e julgar, e de крívw, krínō, de escolher ou decidir. Na verdade, "crítica" tem origem na mesma palavra de raiz. Por outras palavras, longe de significar uma potencial ruptura terminal nas relações sociais ou da psique, crise significa uma perturbação que cria um "espaço" afectivo. Este espaço permite uma análise crítica, que informa as decisões. Em última análise, podemos dizer que uma crise representa uma oportunidade para uma mudança radical. Pensar a crise criando espaço para a reflexão crítica e o julgamento implica uma consideração pela primazia da experiência afectiva da crise. Fraseando diferentemente, a crise é sempre sentida antes de ser compreendida.

A "crise" desempenha também um papel fundamental na etimologia da psicopatologia. Um exemplo relevante e, dada a sua importância para o desenvolvimento da Psicoterapia Institucional, pode ser encontrado no trabalho de Lacan sobre psicose. Para Lacan, a psicose deve ser desencadeada pela con- vergência de uma crise social e mental, a que Lacan se refere como uma "crise da vida", que envolve sempre o desenrolar de relações externas (ou seja, sociais) (Lacan 1993: 17-18). É a isto que Lacan se refere como a psicogênese da psicose. $O$ foco de Lacan tanto na psiquê como no social "equivale a uma teoria estrutural da crise", que puxa imediatamente o trabalho de Lacan para o campo político (Tomšič 2016: 161-162), tornando evidente a sua aplicação tanto ao trabalho terapêutico de Fanon como aos seus compromissos políticos descoloniais.

Perversamente, porém, a psicopatologia foi estrategicamente implantada pela Fran- ça colonial como um mecanismo político para prevenir a crise. Ou seja, a psicopatologia foi utilizada para evitar julgamentos e para confinar indivíduos a espaços disciplinares. Isto foi tornado operável pela 'Ecole psychiatrique d'Alger', a Escola Psiquiátrica de Argel (referida a partir daqui simplesmente como a "Escola de Argel"). A Escola de Argel foi desenvolvida sob a direcção de Antoine Porot na Faculdade de Medicina de Argel e foi inaugurada em 1938 no Hospital Psiquiátrico de Blida-Joinville, o mesmo hospital onde Fanon iria trabalhar mais tarde. Para além do seu papel como a escola de pensamento preeminente na psiquiatria colonial francesa, a Escola de Argel desempenhou um papel específico e importante na dominação colonial francesa. Ao comentar a Escola de Argel e o seu fundador, Richard Keller escreve,

Tal como outros etnopsiquiatras, a obrigação de Porot de tratar os indígenas insanos levou-o a questionar a mentalidade dos argelinos "normais", resultando em conclusões padrão racistas e paternalistas. Com base nas suas observações de fuzileiros argelinos no exército francês, Porot observou que o argelino não tinha qualquer preocupação com o futuro e era intelectualmente infantil, mas sem nenhuma curiosidade natural da criança ou outros bons traços. Além disso, o lunático muçulmano não mostrou nenhum dos "móveis e polimórficos, por vezes ricas psicopatologias do homem civilizado e do europeu". Porot reflete as tendências dos etnopsiquiatras britânicos [...] que concluíram que o nativo era "normalmente anormal". (Keller 2001: 314) 


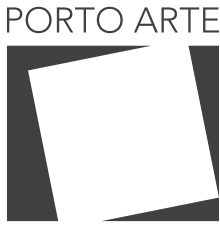

Revista de Artes Visuais

v. 25 n. 44

$\mathrm{Jul} / \mathrm{dez} 2020$ e-ISSN: 2179-8001

Fundir "normais e "patológicas" nas mentes dos argelinos era, de facto, a chave do projecto colonial. Patologizar toda uma população é torná-la legalmente uma criança com uma suposta psique pré-lógica e primitiva (Macey 2012: 222-223), o que significa que Ihes falta uma voz legal e que o Estado é obrigado a cuidar deles, sendo o "cuidado" definido apenas em termos carcerários e pejorativos. Isto foi mais explícito no trabalho de um dos estudantes de Porot, Don Côme Arrii, que escreveu que os argelinos não só eram vulgarmente patológicos, como também nasciam criminosos e, argumentava que o projecto colonial francês era uma missão civilizadora, necessária para preservar a ordem pública da criminalidade indígena (Ibid.: 315). Isto deu justificativa para a criação de uma atmosfera carcerária contida para os povos nativos colonizados, uma colônia penal.

A colônia penal organiza o espaço para criar uma qualidade afetiva, uma estética que cria um ambiente ou uma atmosfera de penalidade. Isto condiciona a formação da subjetividade dentro da colônia, tornando os indivíduos tanto dóceis quanto economicamente "úteis" (Foucault 1995: 250). Assim como o argumento de Arrii de que o colonialismo é uma missão "civilizadora", Foucault traça as origens da prisão até o nascimento do liberalismo, onde a prisão passou a ser "naturalmente" entendida como uma punição "igualitária", a "penalidade das sociedades civilizadas" (Ibid.: 232). A prisão foi baseada, por um lado, em uma formação "jurídico-econômica" e uma formação "técnico-disciplinar", por outro. Esta dupla formação visa punir os indivíduos através da privação de liberdade e, através da punição, conseguir uma transformação técnica civilizatória do indivíduo (Ibid.: 233). Em outras palavras, ao privar um povo da liberdade, a prisão pretende civilizar os indivíduos e torná-los membros economicamente produtivos da sociedade. Dado este entendimento positivista da prisão, não é surpresa que seu nascimento coincidiu com o nascimento da psicologia (Ibid.: 295), do capitalismo moderno (Foucault 2019: 85 - 96) e logo precedeu a reformulação do colonialismo francês como uma missão civilizadora.

Isto não quer dizer, é claro, que a experiência da colônia penal foi igualmente distribuída por todo o estado colonizado. Para que o projeto colonial francês funcionasse, o espaço tinha que ser estratificado de forma a aprisionar as populações indígenas, mas não os colonizadores. Fanon entrou em grandes detalhes descrevendo a bifurcação do espaço colonial, as qualidades estéticas desse espaço, seu ambiente e as formas de violência que esses ambientes produziram no capítulo de abertura de Os Condenados da Terra, "Da violência". Vale a pena citá-lo longamente,

A zona habitada pelos colonizados não é complementar da zona habitada pelos colonos. Estas duas zonas se opõem, mas não em função de uma unidade superior. Regidas por uma lógica puramente aristotélica, obedecem ao princípio da exclusão recíproca: não há conciliação possível, um dos termos é demais. A cidade do colono é uma cidade sólida, tôda de pedra e ferro. É uma cidade iluminada, asfaltada, onde três caixotes do lixo regurgitam de 


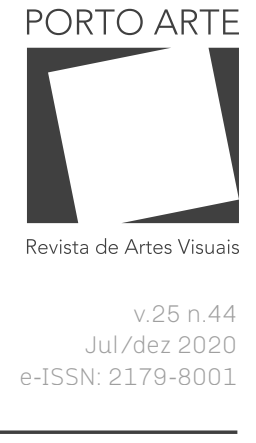

sobras desconhecidas, jamais vistas, nem mesmo sondadas. Os pés do colono nunca estão à mostra, salvo talvez no mar, mas nunca ninguém está bastante próximo deles. Pés protegidos por calçados fortes, enquanto que as ruas de sua cidade são limpas, lisas, sem buracos, sem seixos. A cidade do colono é uma cidade saciada, indolente, cujo ventre está permanentemente repleto de boas coisas. A cidade do colono é uma cidade de brancos, de estrangeiros. A cidade do colonizado, ou pelo menos a cidade indígena, a cidade negra, a medina, a reserva, é um lugar mal afamado, povoado de homens mal afamados. Aí se nasce não importa onde, não importa como. Morre-se não importa onde, não importa de quê. É um mundo sem intervalos, onde os homens estão uns sobre os outros, as casas umas sobre as outras. A cidade do colonizado é uma cidade faminta, faminta de pão, de carne, de sapatos, de carvão, de luz. A cidade do colonizado é uma cidade: acocorada, uma cidade ajoelhada, uma cidade acuada. (Fanon, 1968: p. 28-29) ${ }^{2}$

O mundo colonial racista é um mundo onde o colonizador e as zonas nativas são inversões heterotópicas um do outro, imitando a relação entre a cidade e a prisão. As relações espaciais coloniais produzem formas de homogeneidade racializada que estão embutidas nas práticas espaciais diárias e infundidas nos espaços de representação corporal e afetiva dos colonizados, mesmo quando estão estritamente separadas do colonizador (Kipfer 2005: 711). Fanon continua a argumentar isso,

\begin{abstract}
A originalidade do contexto colonial reside em que as realidades econômicas, as desigualdades, a enorme diferença dos modos de vida não logram nunca mascarar as realidades econômicas. (...) Nas colônias a infraestrutura econômica é igualmente uma superestrutura. A causa é consequuência: o indivíduo é rico porque é branco, é branco porque é rico. (Fanon, 1963, p. 29)
\end{abstract}

A leitura crítica desta passagem, ou "alongamento", da análise marxista conjura um alongamento semelhante da dialética de Hegel em "Pele Negra, Máscaras Brancas" quando Fanon observa que no mundo colonial o Mestre não quer o reconhecimento do Escravo, o Mestre quer o trabalho do Escravo e nada mais (2008: 172). Isto, entretanto, levanta a questão: o que acontece se o sujeito racializado/colonizado for incapaz de ser um trabalhador produtivo devido às necessidades de apoio à saúde mental? Voltando a Foucault, lembre-se de sua observação de que a prisão, as ciências "psi" e o asilo surgiram em uma época que coincidiu com o advento do capitalismo moderno. Sabemos por Foucault que isto não foi, naturalmente, uma coincidência. 


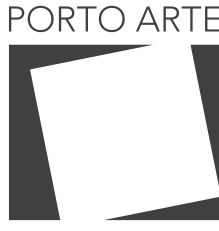

Revista de Artes Visuais v. 25 n. 44 $\mathrm{Jul} / \mathrm{dez} 2020$ e-ISSN: 2179-8001

Pelo contrário, existe uma relação direta entre a demanda do capitalismo por mão-de-obra barata, o nascimento da psiquiatria e o poder carcerário de retirar da sociedade os indivíduos considerados improdutivos. Em outras palavras, há uma relação direta entre loucura, capital e trabalho (Foucault 2006b: Cap. 3).

Um indivíduo é entendido como sendo mais ou menos "anti-social", mais ou menos "violento", mais ou menos "louco" em relação ao arranjo institucional que habita (Fanon 1963: Cap. 1; Foucault 2006b: Cap. 3). É, "sobretudo uma questão de resultados, pois o caráter do marginal foi produzido pelo próprio gesto de segregação". [...] Na realidade, este caráter é meramente o resultado das grades sobrepostas de exclusão" (Foucault 2006a: 79-80). Ou seja, um indivíduo não está em um hospital psiquiátrico porque está mentalmente doente. Eles são doentes mentais porque estão em um hospital psiquiátrico e, onde isso é explicitamente declarado ou não, a razão do confinamento psiquiátrico é provavelmente devido à produção de mão-de-obra improdutiva.

A subjetividade tem uma correlação direta com a privação de liberdade, e o paciente psiquiátrico colonizado/racializado é, portanto, duplamente excluído e confinado. Esta duplicação da exclusão e a privação de liberdade tem um efeito perverso sobre o papel da crise nos discursos de saúde mental. Se aceitarmos a posição de Foucault de que o poder disciplinar da psiquiatria cria corpos dóceis, então a possibilidade de crise é excluída na medida em que o aparelho disciplinar não permite julgamento ou escolha. 0 sujeito colonial/racializado psiquiátrico é mantido em um tipo de animação suspensa, estática tanto no espaço quanto no tempo, privado de crise.

\section{Psicoterapia institucional, ambiente e análise do espaço carcerário}

A experiência da crise existencial assombra a Psicoterapia Institucional. De fato, pode-se argumentar que este movimento nasceu das maiores crises européias do século XX, da Revolução Espanhola e da Segunda Guerra Mundial. A origem da Psicoterapia Institucional pode ser traçada até 1939, na França, no Hospital Saint-Alban com o trabalho de Paul Balvet, François Tosquelles e Lucien Bonnafé (Dosse: 2007, 41). Durante a ocupação, estes médicos foram pioneiros em uma forma de "sócio-terapia", com o objetivo de resistir tanto à ocupação nazista quanto ao sistema de asilo, que eles compararam a um campo de concentração. 0 trabalho realizado em Saint-Alban não só conseguiu proteger seus pacientes dos campos de morte nazistas, mas também se tornou um santuário para a Resistência. Durante este tempo, os que trabalhavam em Saint-Alban formaram a Société du Gévaudan. Com o objetivo de:

\footnotetext{
"resistir e criar": resistir à política de seleção natural que estava matando os doentes mentais, resistir ao regime Vichy que o estava propagando, e resistir às tendências mais amplas de homogeneização e segregação que caracterizam o tratamento dos doentes mentais; criar um convívio terapêutico diante da segregação, e com isto criar uma nova direção na psiquiatria - uma psiquiatria que seria
} 


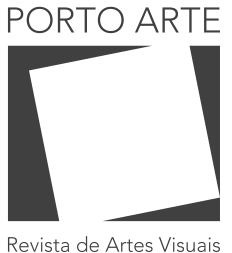

Revista de Artes Visuais

uma "arte de simpatia" viva, não uma alienação, mas um "acompanhamento" da vítima (Novello e Reggio: 2004, 32).

Claude Claverie aprofundou mais sobre isto, escrevendo que a resistência de Saint-Alban à ocupação e confinamento nazistas é o que transformou o hospital em uma comunidade terapêutica.

\footnotetext{
Durante a ocupação, os franceses passaram pela experiência individual e coletiva de um "grande confinamento".A palavra "libertação" teve portanto uma ressonância muito profunda, e seus ecos abalaram as paredes do asilo (para usar uma metáfora heróica, a libertação do asilo foi uma extensão da libertação do país) (Claverie in Macey: 2012, 147).
}

Após a Guerra, dois médicos juniores, Jean Oury e Frantz Fanon, bem como, um pouco mais tarde, um jovem estudante estagiário chamado Félix Guattari veio a Saint-Alban e trabalhou com a Tosquelles para transformar a terapia social que desenvolveram durante a Guerra em Psicoterapia Institucional. A Psicoterapia Institucional não é tanto uma prática coerente, mas um movimento de profissionais da saúde mental politicamente comprometidos (Apprill, no prelo). A abordagem evolutiva que eles utilizam é concebida como uma resistência aos espaços fechados e alienantes criados pelo sistema de asilo como os "campos de concentração" e sociedades que engendram esta forma de segregação. Ela constrói uma inversão heterotópica da sociedade, abrindo contra-espaços, que trabalham para desalienar e des-despersonalizar os pacientes (Tosquelles 2007: 12). A psicoterapia institucional se baseia fundamentalmente na idéia de que o hospital é um microcosmo da sociedade e que o hospital está doente (Oury 2004: 36). Portanto, para curar seus pacientes, eles tiveram que "curar" primeiro o hospital (Ibid.).

O tratamento para o hospital é realizado através da construção do espaço. Não é um espaço geométrico ou arquitetônico, mas, '[...] algo que coloca no lugar um arquiteto de relações, de diferentes papéis, diferentes funções e diferentes pessoas". É uma questão de poder localizar o local no qual algo acontece e o que acontece" (Ibid: 40). Isto implica uma ênfase na vida diária do hospital e na "importância do ambiente em qualquer processo psicoterapêutico" (Oury 2003: 157, minha tradução). Construindo a partir do trabalho de Merleau-Ponty, que foi uma influência importante tanto em Oury quanto em Fanon, Oury define o ambiente como a experiência dos ambientes na vida cotidiana (Ibid.). Isto significa que o espaço é fundamentalmente entendido como o "poder universal" que liga os corpos e as coisas (Merleau-Ponty 2012: 254). Todo conhecimento é estabelecido e depende de nossa percepção do espaço que habitamos (Ibid.: 225), o que significa que o ambiente facilita as ações corporais e as interações sociais, criando hábitos através de associações perceptivas estáveis que antecipam 


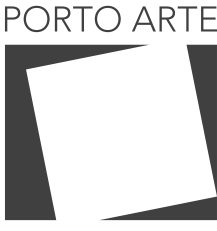

Revista de Artes Visuais

v $25 n \cdot 44$

$\mathrm{Jul} / \mathrm{dez} 2020$ e-ISSN: 2179-8001

as respostas do mundo (Ibid.: 256, 261). 0 ambiente ou atmosfera ${ }^{3}$ criado pelo espaço forma uma relação entre os seres e o mundo e uma compreensão compartilhada do mundo (Chaperot 2014: 193).

O foco analítico sobre o cotidiano é o que sustenta a Psicoterapia Institucional e informa a abordagem de Fanon tanto para a política quanto para a saúde mental. Como Stefan Kipfer corretamente argumenta, "Fanon analisou o racismo cotidiano como uma relação espacial alienante, tratou a colonização como uma organização espacial, e viu a descolonização em parte como uma forma de reapropriação e transformação das relações espaciais na cidade colonial e através da construção de alianças sócio-espaciais nacionais" (Kipfer 2005: 701). De fato, em "Da violência" Fanon analisa como a produção estética das zonas coloniais cria uma atmosfera imbuída de violência e penalidade que serve para, "criar em torno da pessoa explorada uma atmosfera de submissão e de inibição que alivia consideravelmente a tarefa de policiamento" (Fanon 1963: 38). Este poder disciplinar tem um efeito carcerário, selando corpos em posições subalternas (Fanon em Kipfer 2005: 708).

Isto talvez seja mais explícito no capítulo "O Complexo de Dependência dos Povos Colonizados" de "Máscaras Brancas, Peles Negras". Neste capítulo, Fanon argumenta que a formação de complexos de inferioridade nos povos colonizados existe como uma reação à realidade vivida da experiência alienante do racismo e do colonialismo (Fanon 2008: 74). Psicose, Fanon argumenta, entre os povos colonizados é a norma porque o drama racista solto, "está ao ar livre". A pessoa de cor não é capaz de internalizá-lo em seu inconsciente, "tudo é consciente" (Ibid.: 129). Em outras palavras, a doença mental é causada pela alienação do mundo e pela perda da liberdade existencial (Faramelli 2017: 127). Fraseada de forma diferente, a doença mental é uma patologia da liberdade (Bulhan 1985: 247; Macey 2012: 320). A "cura" não pode ser nada menos que a transformação radical da própria sociedade.

\section{Psicoterapia institucional em Blida-Joinville e o paradigma ético-estético de Fanon}

Fanon teve sua primeira experiência clínica de psiquiatria colonial enquanto estudava em Lyon, quando foi chamado para tratar pacientes norte-africanos - principalmente argelinos - reclamando de dores físicas incapacitantes, mas que não apresentavam problemas fisiológicos significativos. Os pacientes que manifestavam estes sintomas viviam nas favelas pobres da Rua Moncey, onde eram submetidos a constante racismo e repressão. Fanon concluiu que embora não houvesse nenhuma razão fisiológica para seus sintomas, seu sofrimento era, no entanto, real. Fanon chamou isto de "Síndrome do Norte da África", um distúrbio psicossomático que afeta a população norte-africana na França, fomentado pelas experiências cotidianas de racismo nas favelas pobres (Macey 2012: 141-142).

\footnotetext{
3- Os termos "atmosfera" e "ambiência" são utilizados de forma intercambiável. Oury usava ambiência em sua escrita e Fanon usava atmosfera, porém em ambos os termos são usados para descrever a forma como um ambiente afeta as ações corporais e as interações sociais.
} 


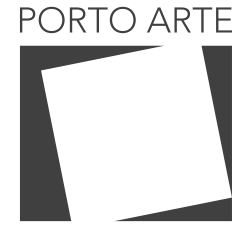

Revista de Artes Visuais

v. 25 n. 44

$\mathrm{Jul} / \mathrm{dez} 2020$ e-ISSN: 2179-8001

A experiência de Fanon com a Síndrome do Norte da África e sua exposição a distúrbios psicossomáticos atuou como cartilha para seu tempo no Hospital Saint-Alban com Tosquelles e Oury e o nascimento da Psicoterapia Institucional (Ibid.: 142). Quando Fanon chegou ao Hospital Psiquiátrico Blida-Joinville em 1953, a perversidade dos espaços confinados do colonialismo francês após a "libertação" da França da ocupação nazista não se perdeu nele, escrevendo que,

Sob a ocupação alemã, os franceses permaneceram homens; sob a ocupação francesa, os alemães permaneceram homens. Na Argélia não há simplesmente a dominação, mas a decisão à letra de não ocupar nada mais do que a soma total da terra. Os argelinos, as mulheres veladas, as palmeiras e os camelos compõem a paisagem, o pano de fundo natural da presença humana dos franceses (Fanon (1963) 2003: 250)

Blida era conhecida como a "capital da loucura" da Argélia, e dizer a alguém que ele deveria estar "em Blida com os loucos" era uma forma convencional de fechar uma discussão (Macey 2000: 212). A estética e o desenho espacial de Blida Joinville eram carcerárias; o hospital era cercado por um alto muro perimetral e um portão supervisionado que o fazia "parecer sinistro" por fora. No entanto, uma vez passado o portão, o hospital era um "ambiente relativamente agradável, um grande parque com instalações esportivas e jardins onde avenidas arborizadas e caminhos ligavam os edifícios de dois andares" (Ibid.: 215).

Fanon chegou a um hospital que estava criminalmente superlotado. Blida-Joinville foi construído para abrigar uma capacidade máxima de 1.200 pacientes. Entretanto, em 1953 tinha 2.200 pacientes (Fanon et. al em Fanon 2018: 396-397). Ao descrever como a superlotação afetou a capacidade do hospital para cuidar dos pacientes, Fanon e seus co-autores escreveram

Como as alas não podem ser ampliadas, mesmo os menores espaços logo se esgotaram. E a enorme superlotação de unidades se tornou tal que a capacidade de regulação planejada quase dobrou em todos os lugares: uma enfermaria de tuberculose projetada para trinta e dois pacientes hospeda setenta e quatro. Uma ala de "pacientes agitados" planejada para quarenta e quatro contém cento e seis pessoas. Uma ala planejada para acolher oitenta pacientes difíceis contém cento e sessenta e cinco, etc. Além disso, o hospital, que no momento da construção foi planejado para 971 pacientes, tem atualmente mais de 2.000. Quase todos os refeitórios, banheiros, etc., foram transformados em dormitórios e, além disso, alguns dos refeitórios não estão mais adequados. Que esperança pode haver para realizar atividades terapêuticas em uma ala de cento e setenta 


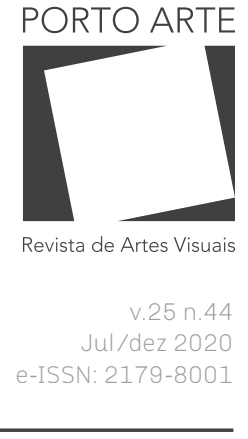

leitos? Há 14 anos, os médicos vêm pedindo à administração que construa oficinas, salas de uso diurno. A capela, construída há vinte anos, não é utilizada apenas para o culto (um padre vem uma vez por mês); ela também foi transformada em um ateliê de ergoterapia, em uma sala de aula para os auxiliares, em uma sala de cinema, etc. Da mesma forma, a mesquita também é utilizada como cesta e oficina de vime; além disso, um mufti vem aqui duas vezes por mês para dirigir orações. Nas enfermarias, muitos pacientes (aqueles que não frequentam a ergoterapia) não têm outra escolha: são atirados para o pátio depois do café da manhã; não há lugar para passar o dia. Os doentes têm poucas opções para se sentarem, a não ser no chão, e o sol na Argélia é muito duro no Verão (Ibid.: 399)

A questão da superlotação foi ainda mais exacerbada pelos sérios problemas com a baixa de pacientes, particularmente os muçulmanos. "Este problema, já tornado difícil devido a algumas realidades de ordem geográfica, torna-se quase intransponível na ausência de qualquer política de assistência e cuidados mentais locais". (Ibid.: 401).

Fanon foi um dos quatro chefs de medicina, juntamente com o Dr Ramee, um estudante de Porot, assim como os médicos Lacaton, Micucci e Dequeber, que eram "metropolitanos" e mais simpáticos à política de Fanon (Macey 2000: 216). As alas de Blida-Joinville foram segregadas segundo linhas étnicas, e Fanon tinha quase 200 pacientes sob seus cuidados: 165 mulheres européias e 22 pacientes muçulmanos do sexo masculino (Ibid.:227). Alguns de seus pacientes eram auto-referidos, porém a maioria tinha sido comprometida com o hospital ou por suas famílias ou pelas autoridades (Ibid.). 0 trabalho da Escola Argel formou a "base doutrinária" para a psicoterapia em Blida e Fanon observou que a atitude tanto de médicos quanto de enfermeiros era baseada em atitudes a priori racistas (Ibid.: 226). No entanto, Fanon se propôs a,

Apresentar os métodos que ele havia aprendido em Saint-Alban. Ele iniciou a primeira experiência em terapia social ou psicoterapia institucional que foi experimentada no Norte da África, e foi observada com uma mistura de hostilidade e diversão por uma equipe acostumada a pensar em termos do paradigma da "escola de Argel". Nenhuma tentativa foi feita para deter Fanon. Como médico-chefe, ele gozou de um considerável grau de autonomia e respondeu ao Governo Geral e não a um professor de psicologia da Universidade de Argel. Os altos funcionários públicos de Argel tinham pouco interesse no que se passava atrás das paredes de um hospital em Blida (Ibid.: 227-228).

Fanon começou a implementar a abordagem da Psicoterapia Institucional com as mulheres européias, estabelecendo um diário semanal de pacientes, uma reunião se- 


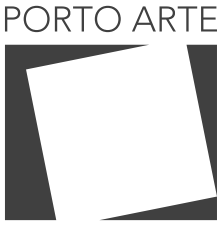

Revista de Artes Visuais

v. 25 n. 44

$\mathrm{Jul} / \mathrm{dez} 2020$ e-ISSN: 2179-8001

manal de pessoal e pacientes que dobrou como um evento social, um cineclube e um clube de discos - com os pacientes escrevendo críticas e respostas a filmes e músicas no jornal da ala -, celebrando coletivamente os feriados - a primeira comemoração desse tipo foi o Natal de 1953, que, por sua vez, inspirou eventos sociais semanais para celebração (Ibid.: 228; Fanon e Azoulay em Fanon 2018: 353-357). A criação de clubes sociais de pacientes no hospital é uma pedra-chave da Psicoterapia Institucional. 0 objetivo é estabelecer um "duplo poder" dentro do hospital a fim de tratar o hospital e o coletivo (Oury 2004: 36; Querrien 2019: 87-93).

Além disso, Fanon criou a ergoterapia e a terapia ocupacional, ambas bem atendidas e que suscitaram respostas positivas dos pacientes (Fanon e Azoulay em Fanon 2018: 356). Este foi um sucesso rápido, com Fanon escrevendo isso,

Assim, desde os primeiros meses, sentimos uma rápida e fecunda aproximação em nossa ala das mulheres européias, como um grupo: a própria atmosfera da ala havia mudado, e pudemos devolver todo o equipamento de contenção sem precisar temer grandes dificuldades. Não só a vida no asilo havia se tornado menos angustiante para muitos, mas o ritmo das baixas já havia aumentado acentuadamente (Ibid.: 357).

O objetivo era afetar o hospital criando novas instituições dentro dele a fim de "transformar a multidão abstrata e impessoal em um grupo coerente movido por preocupações coletivas" (Ibid.: 358). Estas práticas constituem o que Félix Guattari chamaria mais tarde de "ético-estético", práticas de vida criativa - tais como arte, psicanálise, filosofia, etc. - que resistem à colonização da vida à facticidade da biologia e às suas suposições essencializantes. É uma ética da vida que encontra a vida na "novidade de suas formas, em vez de procurar assegurar o futuro contra as mudanças" (Hynes 2013: 1930). A ético-estética procura criar condições institucionais nas quais a psiquê de um indivíduo esteja "conectada a uma gama de registros expressivos e práticos em contrato direto com a vida social e o mundo exterior" (Guattari 1995: 99). Em grande parte esta prática é uma reconceptualização do espaço e, acenando com a influência de Lacan, uma fluidez da significação de um espaço. Vale a pena citar um exemplo deste Guattari que nos dá longamente,

Considere, por exemplo, o sub-conjunto institucional que constitui a cozinha da Clínica La Borde. Ele combina dimensões sociais, subjetivas e funcionais altamente heterogêneas. Este Território pode fechar-se em si mesmo, tornar-se o local de atitudes e comportamentos estereotipados, onde cada um representa seu pequeno ritornelo vazio. Mas também pode ganhar vida, desencadear uma aglomeração existencial, uma máquina de acionamento [...]. A cozinha torna-se então uma pequena cena de ópera: nela as pessoas falam, 


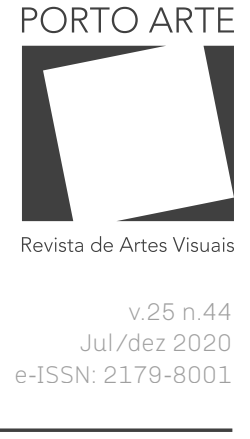

dançam e brincam com todos os tipos de instrumentos, com água e fogo, massa e latas de lixo, de onde emergem relações de prestígio e submissão. Como lugar de preparação de alimentos, é o centro de troca de material e indicativo Fluxos e presenças de todo tipo. Mas este metabolismo do Fluxo só terá significado transferencial na condição de que todo o aparelho funcione efetivamente como uma estrutura que acolhe os componentes pré-verbais dos pacientes psicóticos. Este recurso de ambiência, de subjetividade contextual, é por si só indexado ao grau de abertura (coeficiente de transversalidade) deste subgrupo institucional para o resto da instituição. A semiotização de um fantasma [...] depende, portanto, de operadores externos. O bom funcionamento da cozinha deste ponto de vista é inseparável de sua articulação com os outros núcleos parciais de subjetivação da instituição (o comitê de cardápio, a ficha de atividades diárias, a oficina de pães, a estufa, o jardim, o bar, as atividades esportivas, o encontro entre os cozinheiros e um médico em relação aos pacientes com os quais trabalham...) 0 psicótico que se aproxima de um dispositivo institucional, como a cozinha, atravessa, portanto, uma zona de enunciação bem trabalhada que às vezes pode ser fechada em si mesma e sujeita a papéis e funções, ou encontrar-se em contato direto com Universos de alteridade que ajudam o psicótico a sair de seu aprisionamento existencial. É menos por decisão voluntária do que por indução de um conjunto coletivo inconsciente que o psicótico é levado a tomar a iniciativa, a aceitar a responsabilidade (Ibid.: 69-70 minha ênfase).

Nesta longa citação, Guattari descreve a cozinha de La Borde como sendo parte de um aparelho onde as práticas estéticas externas dentro da instituição são dobradas na significação da cozinha, criando um "ambiente" que permite um maior grau de abertura aos encontros terapêuticos, que Guattari chama de "coeficiente de transversalidade". Em outras palavras, "tratar" a instituição para livrá-la de "estruturas concentracionais" a fim de torná-la um lugar de cura requer práticas estéticas que criem um ambiente que facilite um maior coeficiente de transversalidade, ou uma maior abertura a encontros terapêuticos ao acaso (Oury 2003: 158-159).

Retornando ao trabalho de Fanon no Hospital Blida-Joinville, no artigo "Terapia social em uma ala de homens muçulmanos: Dificuldades metodológicas" Fanon, com Jacques Azoulay, escreve que enquanto a Psicoterapia Institucional obteve grande sucesso com as mulheres européias, os homens muçulmanos a cargo de Fanon não responderam a ela. Eles observam que isto se deve ao fato de que a prática de criar novas instituições deve ser precedida de uma análise e compreensão das sociedades indígenas (Fanon e Azoulay em Fanon 2018: 362). "A socioterapia só seria possível na medida em que a morfologia social e as formas de sociabilidade fossem levadas em 


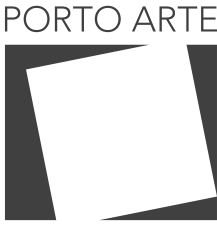

Revista de Artes Visuais

v $25 n \cdot 44$

$\mathrm{Jul} / \mathrm{dez} 2020$ e-ISSN: 2179-8001

consideração" (Ibid.: 364). Eles corrigiram seu curso estabelecendo atividades e criando espaços que eram culturalmente familiares aos homens muçulmanos. Os programas de maior sucesso foram a ergoterapia (especificamente jardinagem), o estabelecimento de um café mouro onde os pacientes podiam jogar dominó e conversar uns com os outros em um espaço decorado com suas próprias pinturas e móveis europeus e tradicionais do Norte da África, e reuniões periódicas em torno de um contador de histórias tradicional (Ibid.: 370-371; Macey 2012: 233). Estas práticas instituíram uma forma de socialidade que gerou o mesmo duplo poder coletivo criado pelos clubes sociais da ala feminina européia.

Esta experiência é frequentemente lida como Fanon ou adaptando uma abordagem cultural relativista à Psicoterapia Institucional ou como o desenvolvimento de uma forma mais igualitária, humanista e etnopsiquiatria (ver Macey 2012: 232). Entretanto, estas leituras não consideram plenamente o papel que a cultura desempenha tanto no colonialismo dos colonizadores quanto na resistência descolonial.David Macey observa que as autoridades coloniais e os administradores do hospital tinham medo de que os homens muçulmanos pudessem usar ferramentas de jardinagem, tendo um café mouro e de contadores de histórias e foram inicialmente resistentes às tentativas de Fanon de introduzi-las na vida diária do hospital (Ibid.: 233). 0 medo que os colonizadores têm da cultura indígena é, de fato, a chave para entender o paradigma ético-estético de Fanon. Como Fanon argumentaria mais tarde (Fanon 1963: "Sobre a Cultura Nacional" e Fanon 1965: "Algeria Unveiled"), o controle da cultura foi a chave para o projeto colonial francês. Ou seja, um aspecto integral do domínio colonial, e, de fato, um dos aspectos talvez mais presentes na colonialidade das instituições contemporâneas, foi a erradicação da cultura indígena e sua substituição pela cultura francófona. Como tal, o desenvolvimento de uma cultura nacional que é ferozmente indígena forma a base para a resistência anti-colonial.

A prática ético-estética é fundamentalmente resistente ao poder carcerário. Isto porque, em seus termos mais simples, a prática ético-estética é empregada para criar o máximo de liberdade. Não apenas a liberdade de movimento, que é obviamente importante, mas, acima de tudo, uma liberdade subjetiva, interna que permite que os indivíduos estejam abertos a encontros terapêuticos fortuitos (Oury 2003: 159). Através destes encontros ocasionais o problema do Mitsein, de estar junto, é resolvido pela formação de um coletivo (Ibid.; Guattari 1995: 70).

A relação entre o "coletivo" - entendida como abrangendo intersubjetividade, processos (micro)sociais e elementos do imaginário social; um conjunto de indivíduos que formula seus próprios projetos, fala e é ouvido, e se coloca em risco ao perseguir seus próprios fins e assumir responsabilidade por eles (Genosko 2002: 9) - não pode ser exagerada. 0 trabalho coletivo abre uma constelação ou um agrupamento de fatores heterogêneos na matriz social ou grupal, permitindo uma liberdade de expressão e a "análise contínua e resistência à alienação social maciça e sua hierarquia" (Oury 2004: 37). Estes encontros - entre médicos e pacientes, mas também entre enfermeiros e outros pacientes - decompõem a relação esquemática de provedor do cuidado e receptor do cuidado em dimensões heterogêneas de conhecimento psiquiátrico, socialidade e 


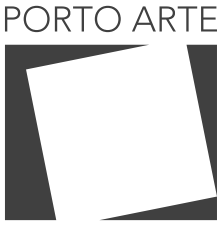

Revista de Artes Visuais

v. 25 n. 44

$\mathrm{Jul} / \mathrm{dez} 2020$ e-ISSN: 2179-8001

um ambiente que apreende diferenças existenciais (Guattari 1995: 70). Isto abre um ambiente de comunicação, perturbando os processos de individualização e alienação enquanto permite uma produção coletiva de subjetividade sui generis (Ibid.: 6).

O que Fanon e Azoulay perceberam através de seu fracasso inicial ao instituir a Psicoterapia Institucional na ala dos homens muçulmanos foi que, apesar de sua intenção, ao organizar atividades européias, estavam reproduzindo inadvertidamente a violência colonial francesa. Portanto, a resistência dos pacientes às intervenções terapêuticas também deveria ser lida como resistência política. Na psicanálise lacaniana, quando o analista se opõe à sugestão do analista, não está resistindo ao analista em si, mas resistindo ao apagamento de seu desejo. Como tal, a resistência transmite o desejo de manter o desejo do sujeito (Wortham 2017: x), criando uma forma de resistência que é operativa tanto no nível inconsciente quanto no nível político (Faramelli, no prelo). O desejo dos homens muçulmanos neste caso era resistir à imposição da cultura colonizadora européia e manter sua própria cultura (Fanon e Azoulay em Fanon 2018: 362). A fim de trabalhar com o desejo dos pacientes de alcançar resultados terapêuticos, Fanon foi forçado a estabelecer novas instituições dentro do estabelecimento do hospital.

É importante esclarecer brevemente a diferença entre um estabelecimento (établissement) e uma instituição. 0 estabelecimento é,

uma estrutura que está mergulhada na sociedade global, e que se relaciona com critérios estatais: deve responder a uma grande quantidade de condições administrativas necessárias; enquanto as instituições são algo que pode se desenvolver dentro do estabelecimento: são quase infinitas em número e variedade" (Oury 1980: xx minha tradução).

Esta compreensão da instituição requer uma atenção especial à micropolítica e às relações de poder (Goffey 2016: 39). Ou seja, ao abordar a psicoterapia, ou qualquer outra prática criativa, com foco nas instituições, força as perguntas: "Quem produz a instituição? Quem articula seus subgrupos?" e "Existe uma maneira de modificar esta produção?" (Ibid.: 40). As instituições são um conjunto maleável de relações, uma espécie de "argila modeladora", que podemos trabalhar para gerar um maior grau de transversalidade em todo o estabelecimento maior (Ibid.: 45). Como tal, as instituições criadas por Fanon, como o café mouro, criaram novas formas de socialidade e uma mudança na atmosfera geral do hospital para além da ala dos homens muçulmanos. Em outras palavras, ao criar novas instituições que afirmaram a cultura argelina, Fanon instituiu um processo maior de purgação das estruturas hospitalares da colonialidade, descolonizando efetivamente o Hospital Blida-Joinville. 


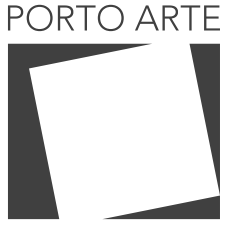

Revista de Artes Visuais

$\vee 25 n .44$

$\mathrm{Jul} / \mathrm{dez} 2020$ e-ISSN: 2179-8001

\section{Porque psicoterapia institucional e porque agora}

Acima e além de tudo, Fanon era um pensador de ambientes. Ele se preocupava principalmente em analisar os ambientes que os diferentes espaços produzem, entendendo como os sujeitos ocupam o espaço de uma clínica e pensando através das maiores questões das relações de poder que os diferentes ambientes geram. De fato, Tosquelles comentou que Fanon "encarnou" (incarnait) o espaço terapêutico (Tosquelles 2007: 9). As relações de poder com as quais Fanon se envolveu são "certamente biopolíticas, mas também envolvem a transformação da terra. 0 objeto do poder neste caso é tanto a vida quanto a terra, e a resistência envolve ambos" (Clare 2013: 62).

Com isto em mente, vemos que sua prática de criar novas instituições destinadas a "curar" o estabelecimento não se limitou à sua prática terapêutica, mas também se estendeu aos seus escritos políticos. Isto talvez seja mais evidente em "Desventuras da Consciência Nacional" de Os Condenados da Terra. Neste capítulo, Fanon, prefigurando o que hoje é chamado de capitalismo racial, analisa como a colonialidade da economia de uma nação perpetua as estruturas neocoloniais maniqueístas de raça, antagonismos raciais e racismo (Fanon 1963: 159). Isto só pode ser subvertido, argumenta Fanon, pela rápida transição de uma consciência nacional que é enquadrada pelo pensamento colonial ocidental para uma consciência política e social descolonizada (Ibid.: 203). Para conseguir isto, Fanon volta a olhar para a prática espacial, argumentando que deve haver "descentralização ao extremo" (Ibid.:198) através da realocação e distribuição de instituições administrativas, estabelecidas em áreas rurais e cidades fora da capital (Ibid.: 185-186). Ao fazer isso, Fanon argumenta que o estado pós-colonial africano criará uma dinâmica de poder transversal que garantirá que a governança e o poder administrativo também sejam descentralizados e distribuídos por toda a população (Ibid.:198).

Ao longo de "Desventuras da Consciência Nacional" Fanon está traduzindo explicitamente as técnicas clínicas da Psicoterapia Institucional em um esquema para o desenvolvimento pós-colonial, a fim de formular uma abordagem psicossocialmente informada para a descolonização das instituições sociais e governamentais. Através da criação de novas instituições no estado pós-colonial Fanon teoriza que haveria um aumento no coeficiente de transversalidade, criando um ambiente de abertura que pode "curar" o estado da mesma forma que as práticas da Psicoterapia Institucional curam o hospital. Isto talvez seja mais explícito em sua discussão sobre o papel que o partido desempenha em relação ao estado pós-colonial quando Fanon argumenta que o partido deve ser independente do governo e sem um líder, a fim de garantir um verdadeiro duplo poder em promulgação (Fanon 1963: 184-186).

Voltando à compreensão da crise acima, podemos pensar ao lado de Deleuze e Guattari e conceituar a crise como uma desterritorialização, um evento que constitui uma ruptura da ordem social e cria um espaço para o julgamento. No entanto, a questão então se torna: onde esta "linha de vôo" vai pousar? Sabemos por Deleuze e Guattari que as desterritorializações não estão em e por si mesmas libertadoras. Elas podem resultar em formações destrutivas autoritárias, mesmo fascistas (Deleuze e Guattari 2003: 192-200; Deleuze e Guattari 2005: 150). 


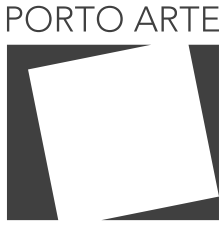

Revista de Artes Visuais

$\vee 25 n .44$

$\mathrm{Jul} / \mathrm{dez} 2020$ e-ISSN: 2179-8001

A convergência das crises que marcou 2020 criou um espaço afetivo onde as mudanças sociais e políticas não só são possíveis, mas inevitáveis. No entanto, oessa mudança será ainda indeterminada. Esta é a razão pela qual é importante revisitar Fanon durante este momento de crise. Ao longo de sua obra, Fanon articula uma ética de vida que não é redutível à mera vida biológica. Ao invés disso, Fanon vê a vida como formada coletivamente em relação a um ambiente (Clare 2013). Em "A Síndrome Norte-africana", Fanon analisa longamente como o ambiente criado pelo racismo colonial isola os norte-africanos que vivem na França tanto dos contatos sociais quanto de seu ambiente (Fanon 1967: 10). Isto resulta em uma espécie de morte viva onde o futuro é excluído (Ibid.: 13). Em contraste, para Fanon, "vida" é entendida como a capacidade de gerar ação e, como tal, tem uma orientação futura (Ibid.: 63-64). Além disso, como Fanon detalha em sua descrição do impulso coletivo para construir uma ponte, a vida é algo que é produzido coletivamente e com uma atmosfera que permite a abertura para encontros fortuitos (Fanon 1963: 141).

Isto é o que Fanon tem a oferecer ao ativismo anti-racista atual. Uma estrutura que seja capaz de analisar a estrutura psicossocial das instituições e formular um programa para a criação de novas instituições. É importante ressaltar que este trabalho já está acontecendo. Um exemplo importante pode ser visto nos crescentes apelos para "não financiar a polícia" ("defund the police")". Além do slogan, o movimento para reestruturar radicalmente o policiamento e realocar fundos para serviços comunitários também perturbará radicalmente a atmosfera de penalidade que constitui a realidade viva para muitas pessoas de cor. Como Homi Bhabha nos lembra, "o estado de emergência também é sempre um estado de insurgência" (Bhabha em Fanon 2008: xxiv ênfase no original), e a leitura de Fanon hoje fornece as ferramentas analíticas para novas instituições transversais criativas.

"A luta contra a opressão colonial muda não apenas a direção da história ocidental, mas desafia sua 'idéia' historicista do tempo como um todo progressivo e ordenado" (Ibid.). Quando uma prática criativa, uma "performance que produz um modo de enunciação desconhecido; um evento coletivo redefine o espaço de possibilidades subjetivas, confronta as pessoas com sua novidade, fala a uma forma de vida ainda por vir" (Hynes 2013: 1940). Isto produz uma temporalidade específica dos paradigmas ético-estéticos, onde o futuro se dobra no presente. Como Bhabha observa em seu avanço para a edição de 1986 de Peles Negras, Máscaras Brancas, é isso que está em jogo em Fanon, o surgimento de uma nova forma de vida (Bhabha em Fanon 2008: xxi-xxxvi). As práticas criativas anti-racistas que nasceram das crises contemporâneas têm agora o potencial de formular um novo paradigma ético-estético, uma nova abertura e liberdade.

4- No Brasil o movimento se organiza ao redor da ideia de um \#FimdaPM, pedindo o fim da polícia militar considerando que a formação policial segue tendo base no período da ditadura brasileira. À exceção das UPPS (Unidadades de Polícia Pacificadora) implementadas no Rio de Janeiro no final da década de 2010 não há um movimento institucional de crítica ou reforma da instituição policial. (N.T.) 


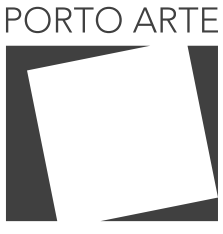

Revista de Artes Visuais

$\times 25 \circ 44$ $\mathrm{Jul} / \mathrm{dez} 2020$ e-ISSN: 2179-8001

\section{Referências}

BULHAN, Hussein (1985) Frantz Fanon and the Psychology of Oppression, Boston: Boston University Press.

CHAPEROT, Christophe (2014) Ambiance et transfert," Formes de transfert et schizophrénie, Paris: Érès.

CLARE, Stephanie (2013) "Geopower: The politics of life and land in Frantz Fanon's writing," Diacritics, vol. 41, no. 4, pp. 60-80.

CAYGILL, Howad (2013) On Resistance: A Philosophy of Defiance, London and New York: Bloomsbury Academic.

DELEUZE, Gilles and Guattari, Félix (2003) Anti-Oedipus: Capitalism and Schizophrenia, Robert Hurley, Mark Seem and Helen R. Lane (trans.), Minneapolis: University of Minnesota Press.

DELEUZE, Gilles and Guattari, Félix (2005) A Thousand Plateaus: Capitalism and Schizophrenia, Robert Hurley, Brian Massumi (trans.), Minneapolis: University of Minnesota Press.

DOSSE, Françoise (2007) Gilles Deleuze and Félix Guattari Intersecting Lives, New York: Columbia University Press.

FANON, Frantz (1963) The Wretched of the Earth, Constance Farrington (trans.), New York: Grove Press.

FANON, Frantz (1965) A Dying Colonialism, Haakon Chevalier (trans.), New York: Grove Press.

FANON, Frantz (1967) Towards the African Revolution, Haakon Chevalier (trans.), New York: Grove Press.

FANON, Frantz (2008) Black Skin, White Masks, Charles Lam Markmann (trans.), New York: Grove Press.

FANON, Frantz (2018) Alienation and Freedom, Khalfa, J. and Young, R. (eds.), Corcoran, Steve (trans.), London and New York: Bloomsbury Academic.

FARAMELLI, Anthony (2018) Resistance, Revolution and Fascism: Zapatismo and Assemblage Politics, London: Bloomsbury Academic.

FARAMELLI, Anthony (2017) "The Decolonised Clinic: Fanon with Foucault," London Journal of Critical Thought, no. 2, pp. 114-128.

FARAMELLI, Anthony (Forthcoming) "Crisis and Resistance," Deleuze and Guattari Studies

FARAMELLI, Anthony, Hancock, D. and White, Rob (2018) "Introduction," Spaces of Crisis and Critique: Heterotopias Beyond Foucault, Faramelli, A., Hancock, D. and White, R. (eds.), London: Bloomsbury Academic, pp. 1-18.

FOUCAULT, Michel (1990) Politics, Philosophy, Culture: Interviews and Other Writings 1977-1984, Alan Sheridan (trans), Lawrence D. Kritzman (ed.), London and New York: Routledge.

FOUCAULT, Michel (1995) Discipline and Punish: The Birth of the Prison, Alan Sheridan (trans), New York: Vintage Books.

FOUCAULT, Michel (1995) "Madness, the Absence of Work," Critical Inquiry, vol. 21, no. 2, pp. 290-298. 


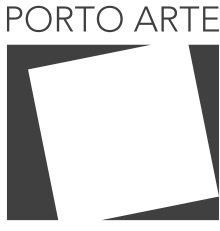

Revista de Artes Visuais $\vee 25 n .44$ Jul/dez 2020 e-ISSN: 2179-8001

FOUCAULT, Michel (2006a) History of Madness, Jonathan Murphy and Jean Khalfa (trans.), Jean Khalfa (ed.), London and New York: Routledge.

FOUCAULT, Michel (2006b) Psychiatric Power: Lectures at the Collège de France 19731974, Graham Burchell (trans.), François Ewald and Alessandro Fontana (eds.), Cham: Palgrave Macmillian.

FOUCAULT, Michel (2019) Penal Theories and Institutions: Lectures at the Collège de France 1971-1972, Graham Burchell (trans.), François Ewald and Alessandro Fontana (eds.), Cham: Palgrave Macmillian.

GENOSKO, Gary (2002) Félix Guattari: An Aberrant Introduction, London and New York: Continuum.

GUATTARI, Félix (1995) Chaosmosis: An Ethico-Aesthetic Paradigm, Paul Brains and Julian Pefanis (trans.), Bloomington: University of Indiana Press.

HYNES, Maria (3013) "The ethico-aesthetics of life: Guattari and the problem of bioethics," Environment of Planning A, vol. 45, pp. 1929-1943.

KELLER, Richard C. (2007) "Clinician and Revolutionary: Frantz Fanon, Biography, and the History of Colonial Medicine," Bulletin of the History of Medicine, vol. 81, n. 4 , pp.823-841.

KIPFER, Stefan (2005) "Fanon and space: Colonization, urbanization, and liberation from the colonial to the global city," Environment and Planning D: Society and Space, vol. 25, pp. 701-726.

LACAN, Jacques (1993) The Seminar of Jacques Lacan Book III The Psychosis 19551956, Miller, Jacques-Alain (ed.), Grigg, Russell (trans.), London and New York: Norton and Company.

MACEY, David (2012) Frantz Fanon A Biography, London and New York: Verso,

MERLEAU-PONTE, Maurice (2012) Phenomenology of Perception, Donald A. Landres (trans), London and New York: Routledge.

NOVELLO, Mauricio and Reggio, David (2007) in Oury, Jean (2007) "The Hospital is Ill," Radical Philosophy, Novello, Mauricio and Reggio, David (trans.), n.143, pp. 32-45.

OURY, J. (2003). "Transfert, multiréférentialité et vie quotidienne dans l'approche thérapeutique de la psychose," Cahiers de psychologie clinique, (21), pp. 155-165.

OURY, J. (2007) "The Hospital is Ill," Radical Philosophy, Novello, Mauricio and Reggio, David (trans.), n.143, pp. 32-45.

QUERRIEN, Anne (2019) "La pluralité des pouvoirs au fondement du Club," Chimères, no. $95, \mathrm{pp} .87-93$.

TOMŠIČ, Samo (2016) "Psychoanalysis, capitalism, and the critique of political economy: Toward a Marxist Lacan," Jacques Lacan Between Psychoanalysis and Politics, Tomšič, S. and Zevnik, A. (eds.), London and New York: Routledge, pp. 146163.

TOSQUELLES, François (2007) "Frantz Fanon et la Psychothérapie institutionelle," Sud/ Nord, vol. 1, n. 22, 71-78.

WORTHAM, Simon (2017) Resistance and Psychoanalysis Impossible Divisions, Edinburgh: University of Edinburgh Press. 


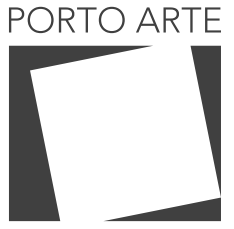

Revista de Artes Visuais

v. 25 n. 44 Jul/dez 2020 e-ISSN: 2179-8001

Texto submetido em: 22/12/2020 Texto publicado em: $30 / 12 / 2020$

\section{Anthony John Faramelli}

Acadêmico cuja abordagem é interdisciplinar por natureza. Trabalha nas áreas entre mídia, teoria social, estudos culturais, estudos psicossociais, estudos de ciência e tecnologia e política. Grande parte da sua pesquisa se concentra em Análise Institucional, esquizoanálise e no trabalho feito por Frantz Fanon, Félix Guattari, François Tosquelles e Jean Oury. Seu trabalho também se cruza com questões relativas ao zapatismo, descolonização, estética, teoria política e resistência indígena. 